\title{
MAPEAMENTO DE TENDÊNCIAS NA PRODUC̣ÃO ACADÊMICA SOBRE EDUCAÇÃO AMBIENTAL ${ }^{1,2}$
}

\author{
Claudia Pato* \\ Lais Mourão Sá** \\ Vera Lessa Catalão***
}

RESUMO: Este trabalho procurou configurar o cenário das pesquisas apresentadas na área de Educação Ambiental - EA nas reuniões anuais da Associação Nacional de PósGraduação e Pesquisa em Educação - Anped, no período de 2003 a 2007, a partir da solicitação do grupo de EA da Anped (GT-22). Buscou-se, com isso, elucidar as tendências temáticas, teóricas e metodológicas na produção acadêmica sobre EA e compreender a diversidade que constitui esse campo de investigação e de ação pedagógica. Foram considerados 66 trabalhos apresentados nas cinco reuniões analisadas. Os resultados foram articulados considerando-se: evolução da temática; linha temporal associada à diversificação temática, teórica e metodológica; localização espacial; e articulação entre as áreas ambiental, de educação e de EA. Observa-se concentração da produção no eixo sul-sudeste do Brasil, predominância da abordagem socioambiental e de uma visão crítica da EA ao longo dos anos e ênfase na educação formal e no método qualitativo.

Palavras-chave: Educação Ambiental; Tendências na Pesquisa em Educação Ambiental; Campo Socioambiental.

\section{MAPPING TRENDS IN ACADEMIC PRODUCTION ON ENVIRONMENTAL EDUCATION}

ABSTRACT: This paper was aimed at setting the stage research in Environmental Education - EE in the annual meetings of the National Association of Graduate Studies and Research in Education between 2003 and 2007, following requests from the area working group (WG-22). Our goal was to elucidate thematic, theoretical and methodological trends in academic research in EE, and to understand the diversity of this research field and pedagogical action. For the analysis we considered 66 papers presented in the five meetings. The results were articulated considering: thematic evolution; timeline regarding theme, theory and methodology diversification; spatial location; and

* Doutora em Psicologia pela Universidade de Brasilia (UnB); Professora na Universidade de Brasilia (UnB).E-mail: claudiap@unb.br

** Doutora em Antropologia pela Universidade de Brasilia (UnB); Pós-Doutorado em Ciências Sociais e Meio Ambiente pela Universidade Estadual de Campinas (UNICAMP); Professora Adjunta da Universidade de Brasilia (UnB).E-mail: lais.maria@terra.com.br

*** Doutora em Ciências da Educação na área de Approches de la Complexité Educative Université Paris VIII. Professora da Universidade de Brasilia (UnB). E-mail: vera.catalao@terra.com.br 
the connections between environmental, educational and EE. It was evident a concentration of production in the southern and southeastern areas of Brazil, the prevalence of a socioenvironmental approach and a critical view of EE over the years, as well as the emphasis on formal education and qualitative methodology.

Keywords: Environmental Education; Research trends in Environmental Education; Socioenvironmental Field.

\section{Introdução}

A Educação Ambiental - EA brasileira, especialmente a partir da Conferência Rio-92, vem agregando notável conteúdo político a sua práxis, reconhecendo-se como prática social inserida em ampla e complexa trama relacional, marcada por conflitos socioambientais e crise de valores.

Em 2003, quando a EA constitui-se como Grupo de Estudos na Associação Nacional de Pós-Graduação e Pesquisa em Educação ANPED, após alguns anos de apresentação de pesquisas e ensaios sobre o tema em outros Grupos de Trabalho dessa instituição, um longo caminho já havia sido trilhado, no sentido de construir uma identidade político-pedagógica para as atividades de pesquisa em EA no Brasil.

Essa temática, originária do campo das ciências biológicas, vem se consolidando no campo das ciências humanas, em especial no da educação, ao tempo em que se caracteriza pela ausência de um fundamento único, garantindo, assim, a multiplicidade de sentidos em disputa (CARVALHO, 2006, p. 33).

Para Sato e Santos (2003, p. 254), no final do século XX a EA deu um salto qualitativo, passando do "conservacionismo extremo a uma compreensão mais ampla de ambiente e natureza", e o surgimento do termo socioambiental denota essa mudança de perspectiva no Brasil e na América Latina.

O diálogo entre esse campo socioambiental e o campo educacional, tema constitutivo da área desde sua instituição na Conferência de Tbilisi, situa-se em esfera interdisciplinar, criando uma área de confluência marcada pela pluralidade temática, pela abordagem socioambiental mais ampla e pela abertura epistemológica, que legitima as trocas e a complementaridade de saberes.

Longe de ser uma nova área disciplinar, a EA procura pensar-se como um campo de inovação e articulação capaz de fertilizar outros 
campos de saberes. Nesse sentido, surgem algumas questões, como, por exemplo, como essa área de confluência se constitui e que tendências são evidenciadas nessa esfera dialógica entre educação e meio ambiente. Além disso, que significados, temas, discussões, campos teóricos e práticas metodológicas se anunciam. É possível identificar autores, conceitos teóricos e metodologias dominantes ou a pluralidade é inerente a essa área? Que linhas transversais integram a diversidade do campo?

Diante dessa realidade e em consonância com esses questionamentos, surgiu o convite do Grupo de Trabalho em Educação Ambiental da Anped (GT22) para a realização de um mapeamento das tendências na produção acadêmica da área, apresentadas no período de 2003 a 2007, nas reuniões anuais dessa instituição.

Para atender à demanda e responder às questões identificadas como pertinentes, a produção acadêmica objeto do presente trabalho foi analisada em etapas, considerando-se três eixos específicos: tendências temáticas, teóricas e metodológicas. Foram realizadas análises preliminares desses trabalhos, a partir das quais foram elaborados resumos descritivos de cada um deles. Em seguida, foram criadas categorias de análise para interpretação das tendências nos três eixos de referências, buscando-se preservar a singularidade da análise de cada eixo.

O sentido de mapeamento apontou para a necessidade de localização temporal e espacial dessa produção e para a identificação de linhas transversais de articulação. Para análise e interpretação dessa cartografia foram utilizadas quatro categorias que orientaram a descrição e a reflexão sobre cada um dos eixos: 1) Evolução da temática EA na estrutura da Anped; 2) Linha de tempo associada à diversificação temática, teórica e metodológica; 3) Localização espacial da produção acadêmica apresentada; e 4) A articulação entre a área ambiental, a de educação e a de educação ambiental.

Tendo como referência essas quatro categorias de análise, serão apresentados a seguir os três eixos específicos, com suas características e singularidades. 


\section{Eixo 1 - Tendências temáticas}

O mapeamento das tendências temáticas em EA nos trabalhos apresentados na Anped foi organizado em dois períodos distintos: o primeiro abrange os anos de 2003 e 2004, quando surge o grupo de estudos (GE) em EA; no segundo período, de 2005 a 2007, a EA adquire o status de grupo de trabalho (GT).

Os temas recorrentes foram identificados e inseridos em uma linha temporal, observando-se a evolução da pesquisa em EA na Anped e a localização espacial que identifica a procedência dos trabalhos apresentados.

O ano de 2003, que marca o início do Grupo de Estudos em EA nos encontros anuais da Anped, teve treze trabalhos apresentados, entre artigos e pôsteres. Destes, doze trabalhos foram de universidades do Sudeste e do Sul do país e uma única contribuição era da região Norte.

Os temas foram distribuídos em reflexão teórica sobre fundamentos da EA (conceito de natureza, correntes de EA, sustentabilidade, transdisciplinaridade, paradigma complexidade); ética e formação de valores; representação social sobre meio ambiente; relatos de pesquisas em EA desenvolvidas em espaços formais e não-formais; e formação de educadores. As concepções ambientais dos povos indígenas sobre meio ambiente constituiu o tema do único trabalho apresentado pela região Norte, oriundo da Universidade Federal do Amazonas. Representações sociais e pressupostos teóricos do campo do conhecimento pedagógico da EA foram utilizados para o estudo das percepções de professores dos cursos de Biologia, Química e Geografia de universidades públicas do estado de São Paulo.

Foi possível constatar uma distribuição bem-equilibrada entre os estudos teóricos (6), as pesquisas em espaços de educação formal (8) e as realizadas em espaços não-formais (5), ainda que haja ligeira predominância da pesquisa sobre Educação Ambiental em espaços de educação formal.

O cenário desse primeiro ano do GE em EA na Anped sugere que a pluralidade temática e a complementaridade de conhecimentos constituem o perfil do campo ecológico-ambiental quando este interage com a educação.

Entre os estudos teóricos, nenhum tema teve ocorrência preponderante. Transdisciplinaridade, complexidade, mudança de paradigma, 
ética, concepções de natureza e cultura, sustentabilidade e representações sociais constituem o universo da expressiva pluralidade temática do campo nesse período.

Observa-se que o estudo das representações sociais apareceu em três trabalhos, enquanto que a produção de materiais didáticos de EA foi tema isolado. Com relação à educação formal, os temas interdisciplinaridade, construção da identidade, cidadania e formação de educadores marcaram presença. As questões pedagógicas em ambientes formais e não-formais de aprendizagem ocuparam significativamente o foco das pesquisas e dos debates ambientais, tornando-se campo fecundo de interlocução entre a educação e os problemas socioambientais.

Essa diversidade confirma a EA como cenário epistemológico marcado pela pluralidade temática e pela convergência de múltiplos campos de saber articulados à mudança da relação homem/natureza. A questão ética apareceu de forma transversal, como principio que sustenta a reflexão sobre a ação humana no mundo, a partir dos próprios sentidos dados pela comunidade.

No ano seguinte (2004), foram analisados quatorze trabalhos e, mais uma vez, predominaram as regiões Sul e Sudeste, com doze trabalhos, enquanto o Norte e o Nordeste tiveram dois artigos apresentados.

As pesquisas voltadas para as relações entre as questões ambientais e a educação formal corresponderam a $50 \%$ do total dos trabalhos apresentados, que versaram sobre o cotidiano escolar e o currículo. A pesquisa sobre EA em espaços educativos não-formais respondeu por apenas 14\% de artigos e pôsteres selecionados. Os ensaios teóricos abordaram fundamentos e conceitos de EA, o papel da subjetividade e das representações sociais sobre meio ambiente, o papel da cultura e dos padrões relacionais entre sociedade e natureza, complexidade e sustentabilidade ambiental.

Um dos artigos abordou diretamente a contribuição da antropologia da ciência para discutir a distinção entre biológico e social. Pela primeira vez, tomou-se o campo do trabalho para problematizar as concepções e as práticas de EA e os sentidos contraditórios dos conceitos de desenvolvimento sustentável. Outros temas transdisciplinares, como globalização, cidadania e desenvolvimento sustentável, também foram abordados pelos ensaios teóricos nesse período. 
Percebe-se que o entendimento sobre os problemas ambientais passa por uma concepção de meio ambiente como campo de conhecimento e de significados construídos socialmente, a partir de uma pluralidade de relações entre cultura, natureza e meio ambiente.

A complexidade inerente aos processos educativos e aos processos socioambientais apareceu como tema em diversos trabalhos, mostrando um espaço de interlocução reflexiva na pesquisa e na discussão pedagógica em EA. A reflexão sobre formação dos professores e representações sociais de estudantes, professores e educadores ambientais pontuou o universo temático da pesquisa no ano de 2004.

As discussões sobre interdisciplinaridade, transdisciplinaridade e práxis educativa apresentaram-se como foco temático em grande número de artigos, na perspectiva de rede de conhecimentos e de comunidade ecológica. O conhecimento em rede e a teia da vida se retroalimentam e produzem uma reflexão duplamente enraizada nas bases biológica e antropossocial.

É notável que somente um trabalho apresentado refere-se à Educação Ambiental em Unidades de Conservação, analisando os programas de EA desenvolvidos tendo como referência as recomendações da Conferência Intergovernamental de Educação Ambiental de Tbilisi (1977).

A compreensão do campo ambiental como construção social foi diretamente enfocada em três trabalhos, aparecendo pela primeira vez a denominação "socioambiental" no título de artigos e como foco de reflexão. A pesquisa-ação e as pesquisas participantes foram temas de pesquisa e reconhecidas como metodologias mais apropriadas à construção de conhecimentos em EA. O desenvolvimento sustentável foi discutido criticamente, sendo inserido no âmbito do processo de globalização e do mundo do trabalho.

O ano de 2005 marcou a passagem de GE para GT (22) de Educação Ambiental na Anped. Foram analisados dez trabalhos, todos procedentes do Sudeste e do Sul do país. Os artigos apresentados mostraram formatação padronizada e pode-se perceber a preponderância das discussões pedagógicas no campo da EA.

Os debates sobre abordagem epistemológica e correntes de EA encorparam-se e apareceram como tema de três trabalhos. A fenomenologia, a hermenêutica e a teoria das representações sociais 
apareceram pelo terceiro ano consecutivo como temática de estudos. A constituição identitária do campo da EA foi problematizada em dois estudos sobre as identidades do educador ambiental e na formação inicial e continuada de professores.

A contribuição da arte em Educação Ambiental apareceu como tema emergente, com foco no texto literário e na contribuição da estética para a sensibilização ambiental. O debate sobre valores éticos e estéticos em EA foi o tema de um trabalho, que discutiu a formação continuada de professores. Pela segunda vez a cultura indígena apresentou-se como tema de discussão, dessa vez abordando saúde e saneamento em comunidades indígenas.

Em 2006, nos dezesseis trabalhos analisados, confirmou-se a prevalência de instituições acadêmicas do Sudeste e Sul. Somente dois trabalhos foram provenientes da região Nordeste. Pode-se observar a tendência crescente de pesquisa de campo e a menor incidência de ensaios teóricos. Nestes, predominam a reflexão sobre concepções de natureza, de cultura e de educação, em um movimento notável de construção de identidade desse novo campo de pesquisa e reflexão.

As pesquisas sobre o contexto escolar constituíram 50\% dos trabalhos apresentados, com destaque para um novo veio temático acerca da EA no ensino médio, na perspectiva da construção da cidadania, e de um artigo que tratou da contribuição da filosofia para a formação discente em EA.

Os demais trabalhos apresentados discutiram aspectos teóricos sobre fundamentos da EA (paradigma, complexidade, sustentabilidade e transdisciplinaridade), desenvolvimento e preservação ambiental e sobre atuação de movimentos sociais e ONGs ambientalistas nos espaços nãoformais de EA. Pela segunda vez - a primeira foi em 2003 -, discutiu-se a EA na mídia televisiva. Nesse caso, o foco foi as produções da TV Cultura. Essa temática apareceu de forma isolada, não se constituindo uma tendência expressiva.

Em 2007, foram analisados treze trabalhos, entre artigos e pôsteres, que confirmaram mais uma vez a tendência consolidada de localização da pesquisa acadêmica nas regiões Sul e Sudeste. O Centrooeste teve sua primeira aparição, com uma produção da Universidade de Brasília, e a região Nordeste apareceu com uma única contribuição da Universidade Federal do Ceará. 
A formação de professores apresentou-se como temática predominante: formação de professores na Educação de Jovens e Adultos, capacitação de professores das séries iniciais, formação de professores e transição de paradigmas, tendências da formação docente e das práticas de EA e a formação em EA no ensino superior constituíram os diversos enfoques de abordagem do tema.

Educação Ambiental libertária e os fundamentos teóricos para uma pedagogia crítica da EA marcaram a produção de 2007. Esse veio temático vem reafirmar a recorrência dos temas pedagógicos e o reconhecimento da EA como espaço de mediação entre a escola e os problemas ambientais contemporâneos. Outra linha temática expressiva, que aparecia com menos ênfase em outros trabalhos, surgiu como tema central de discussão. Trata-se da relação entre EA e Educação Popular em processos de alfabetização. Ao mesmo tempo, percebe-se a redução gradativa de temas que associam Educação Ambiental com o estudo das ciências da natureza.

Construção de conhecimento, transição de paradigmas, cidadania e práxis pedagógica constituíram o foco de outros estudos analisados, que se situam na zona de articulação entre Educação Ambiental, educação e meio ambiente. As origens do distanciamento entre sociedade e natureza foram estudadas a partir da percepção ambiental de frequentadores de um Parque Municipal e de um estudo teórico que discute o sentido da outridade na relação homem e natureza no contexto do currículo do ensino médio.

As temáticas apresentadas na Anped no período de 2003 a 2007 estão em consonância com as apresentadas no Colóquio Internacional em Pesquisa sobre Educação Ambiental, realizado em Montreal, em 1997. Segundo Sauvé (apud Sato e Santos, 2003, p. 257), as temáticas desse evento foram predominantemente marcadas por temas pedagógicos, formação de educadores e currículo (45\%), seguidas por discussão sobre fundamentos de EA, sociologia, filosofia, valores, atitudes (19\%). As representações sociais estiveram presentes em 11\% dos trabalhos, com incidência maior do que observamos na Anped.

Observa-se, no caso brasileiro, a tendência insurgente voltada para o estudo da Educação Ambiental não-formal, especialmente em comunidades tradicionais e movimentos sociais. Além disso, há recorrência da pesquisa-ação como temática específica de alguns 
trabalhos, delineando-se uma possível identidade para a EA no Brasil, que vai além do somatório de produções individualizadas.

Essas tendências temáticas identificadas podem ser mais bemcompreendidas a partir da análise do campo teórico e do metodológico, enfocados nos próximos eixos de referência que estruturaram o presente trabalho.

\section{Eixo 2 - Tendências teóricas}

A análise das tendências teóricas do conjunto de trabalhos apresentados no GT22 durante o período de 2003 a 2007 foi realizada a partir do seguinte procedimento metodológico:

Um primeiro nível de abordagem constou da elaboração de uma lista geral de todas as bibliografias dos trabalhos de cada ano. A intenção desse procedimento foi gerar unidades de significação que permitissem a leitura transversal para o tratamento das questões teóricas para além da referência particular de cada trabalho. As cinco totalidades bibliográficas específicas geradas a partir desse procedimento foram denominadas "períodos bibliográficos", para articular o sentido de unidades temporais formadas a partir de listas de bibliografias de cada encontro.

Em cada um desses períodos bibliográficos foram identificados os campos teóricos que pudessem ser tratados como unidades conceituais gerais. Os quatro grandes campos teóricos identificados nesse nível foram:

- Conceituação de Educação Ambiental.

- Conceituação de educação.

- Complexidade e construção do conhecimento.

- Articulações entre os campos teóricos da ecologia, da cultura, da política, da ética e do meio ambiente.

Outra sequência de campos teóricos, que se chamará de emergentes, diferenciou-se pelo fato de emergirem com suas especificidades no interior de alguns períodos bibliográficos, apresentando relativa autonomia teórica quanto aos quatro grandes campos teóricos principais. São eles, identificados pelo período em que aparecem:

- Educação e saúde - 2004 e 2006.

- Questões indígenas no currículo escolar - 2003. 
- Ensino de ciências - 2004, 2005, 2007.

- Representações sociais - 2004, 2005, 2006.

- Sustentabilidade, regionalização, políticas ambientais - 2003, 2005, 2006.

- Filosofia e natureza - 2003, 2005, 2006.

- Fundamentos de dinâmicas de grupo - 2004.

- Educação e novas tecnologias - 2006.

- EA e literatura brasileira- 2005 e 2006.

- EA e questões urbanas - 2006.

Um terceiro nível de abordagem buscou identificar autores e categorias conceituais específicas que fundamentam a construção de cada campo teórico delimitado. Nesse nível, tornou-se possível compreender o modo específico de construção dos objetos de análise e o lugar atribuído aos autores e suas teorias nessa construção. Nesse sentido, foram listados para cada campo teórico:

- Autores que aparecem em todos os períodos bibliográficos; são autores que se tornaram referências obrigatórias no decorrer do processo de construção do debate em cada campo teórico.

- Como complemento a essa classificação, foram identificados também autores que aparecem em pelo menos três períodos bibliográficos, o que permite identificar a partir de que momento eles passam a figurar a lista dos principais autores de cada campo teórico.

- Subcampos teóricos específicos que emergem de modo intermitente e teoricamente integrados, no interior dos campos teóricos principais, não chegando, porém, a ganhar autonomia suficiente para se constituir como campos autônomos.

\section{Os quatro grandes campos teóricos}

\section{Campo teórico da Educação Ambiental}

No que se refere à conceituação estrita de EA, encontrou-se um conjunto de sete autores cuja referência foi recorrente nas totalidades bibliográficas consideradas. São eles: Carlos F. B. Loureiro, Genebaldo F. Dias, Marcos Reigota, Marcos Sorrentino, Mauro Grün, Michele Sato e Philipe P. Layrargues. 
Um indicador que permite traçar um diferencial entre esses autores é o fato de que alguns deles estavam publicando no intervalo de tempo considerado para análise e algumas dessas obras foram, inclusive, publicadas no próprio GT22. É o caso de Layrargues, Loureiro, Sato e Sorrentino.

Outros autores que completam essa lista, com referências em pelo menos três períodos bibliográficos, são: Isabel C. M. Carvalho, a partir de 2005; Mauro Guimarães e Lucie Sauvé, a partir de 2004; e Carlos R. Brandão, a partir de 2006.

Com relação aos subcampos teóricos que emergiram no campo teórico da EA, têm-se as seguintes configurações:

- Autores que são referência nas questões relativas à EA na escola e à formação de professores: Manzochi, L. H. (2003 e 2005); Spazziani, M.L. e Sorrentino, M. (2004 e 2006); Tamaio, I. (2004 e 2006); Zakrzevski, S. (2005 e 2007).

- No período bibliográfico de 2004, a tematização teórica dos fundamentos pedagógicos e da complexidade no campo científico para uma reflexão sobre a EA destaca referências a obras de Isabel Carvalho e de Enrique Leff.

\section{Campo teórico da educação}

Esse campo aporta conceitos pedagógicos que fundamentam a construção das questões da EA sobre escola e formação de professores. Paulo Freire foi referência recorrente nas totalidades bibliográficas consideradas. Outras referências que apareceram em pelo menos três períodos bibliográficos foram Demerval Saviani, Edgar Morin, Humberto Maturana e Moacir Gadotti, a partir de 2004.

Com relação aos subcampos teóricos que complementam e especificam a busca por fundamentos na área da educação, têm-se as seguintes configurações, em que se destacam os principais autores:

- Antropologia e filosofia da educação (2003 e 2004): Carlos Brandão, Francisco Gutierrez, Jean Piaget, L. Vygotski, M. Manacorda.

- Formação de professores, suas representações e práticas (2004, 2005, 2007): Miguel Arroyo, Ubiratan D’Ambrosio, Fávero e Nóvoa.

- Ética e filosofia da educação (2006): Antonio Severino, 
Boaventura de S. Santos, Francisco Gutiérrez, Gaston Pineau, Michel de Certeau, M. Manacorda, Maria Cândida de Moraes, Theodor Adorno.

- Arte, subjetividade e sensibilidade na educação (2005, 2006, 2007): Antonio Damásio, Hugo Assman, Jorge Larrosa, L. Vygotski, Pierre Galvani, Serge Moscovici.

- Processos político-pedagógicos (2007): Ivani Fazenda, J. C. Libâneo, Luiz Carlos Freitas, M. Enguita, Silvio Gallo, P. Perrenoud, Tomas Tadeu Silva.

\section{Complexidade e construção do conhecimento}

Este campo teórico também se constitui como um importante fundamento das questões da EA, articulando recortes sobre as relações entre ciência e sociedade, epistemologia ambiental, inter e transdisciplinaridade, teoria crítica, psicologia e psicanálise.

Os autores que apareceram como referências principais foram Edgar Morin (em todos os períodos bibliográficos), Enrique Leff (em quase todos - menos 2006), Boaventura de S. Santos (2004, 2006 e 2007) e Karl Marx (2003, 2004 e 2006).

Como subcampos teóricos que indicam especificidades dos períodos considerados, têm-se:

- 2003 - Psicanálise e representação social, e epistemologia ambiental: F. Capra, S. Moscovici, I. Prigogine.

- 2004 - Mente, consciência e sociedade; interdisciplinaridade; ciência, sociedade e natureza; psicologia, pensamento e linguagem - P. Bourdieu, A. Damásio, H. Japiassu, T. Khun, B. Latour, L. Vygotski.

- 2005 - Emoções e linguagem na formação; complexidade ambiental - H. Maturana.

- 2006 - Educação e transdisciplinaridade; complexidade e conhecimentos rivais - F. Capra, I. Prigogine, Ciurana, Nicolescu, Patrick Paul.

- 2007 - Hermenêutica; ciência, direito e política - R. Bernstein, E. R. Ciurana, B. Nicolescu, Patrick Paul. 


\section{Articulações entre os campos teóricos da ecologia,} da cultura, da política, da ética e do meio ambiente

Esse campo teórico tem maior complexidade que os anteriores, no sentido de que apresenta grande aporte de disciplinas e áreas interdisciplinares convergentes, tratadas como fundamentos para as questões de meio ambiente e educação.

Os autores que apareceram como referências principais foram Anthony Giddens, Felix Guattari, Giles Deleuze e Henri Acselrad (em quatro dos cinco períodos bibliográficos); Boaventura de S. Santos (2004, 2005 e 2006) e Antonio Carlos Diegues (2004, 2006 e 2007).

Como subcampos teóricos interdisciplinares específicos, que emergiram nessa categoria, têm-se:

- Globalização, desenvolvimento e crise ecológica: Amartya Sen, C. Castoriadis, C. Darwin, C. W. Porto-Gonçalves, G. Foladori, I. Sachs, J. Lovelock, J. Lutzemberger, Milton Santos, R. Carson.

- Democracia, participação, políticas públicas: E. Viola e H. Leis, Emir Sader, J. A Pádua, M. Chauí, O. Ianni, P. Demo, P. Jacobi, Paul Singer, H. Arendt.

- Capitalismo, modernidade, trabalho e alienação: Adam Smith, F. Hayeck, I. Mészáros, M. Bookchin, M. Hardt e A. Negri, N. Elias, R. Antunes, U. Beck, Weber.

- Cultura, modernidade, natureza e sociedade: A. Corbin, A. Schopenhauer, A. Touraine, C. Geertz, C. R. Brandão, F. Nietzsche, G. Canclini, G. Durand, H. Lefebrve, I. Prigogine e I. Stengers, J. Habermas, M. Augé, M. Certeau, M. Maffesoli, P. Tompson, S. Hall, S. Moscovici, T. Adorno.

- Ecologia e educação, saber ambiental, psicologia, ecologia humana, eco-socialismo, ecologia profunda: D. Pepper, E. Bosi, E. Leff, G. Bateson, H. Maturana, I. Carvalho, J. Jung, M. J. Lima, Marcos Sorrentino, S. Lane e B. Sawaia. 


\section{Campos teóricos emergentes}

Como foi dito, trata-se de campos teóricos que emergiram em determinados momentos da totalidade de períodos considerada, com especificidade epistemológica que os delimita e diferencia. Sua relativa autonomia conceitual justifica situá-los em categoria distinta dos campos teóricos principais.

1 - Educação e saúde é um campo teórico emergente nos períodos bibliográficos de 2004 e 2006, que apresenta nitidamente dois subcampos específicos:

Saúde e meio ambiente: traz enfoques teóricos sobre currículo da escola pública, direito e cidadania nas classes populares, formação de agentes comunitários, saneamento, saúde pública, nutrição. Dois principais espaços acadêmicos se destacaram na produção científica desse campo:

- A Faculdade de Saúde Pública da USP e o seu Núcleo de Informações em Saúde Ambiental (NISAM), com pesquisas de mestrado, doutorado (A.F.Pelicioni) e livre-docência (M.C.F. Pelicioni).

- A PUC-Rio, com as pesquisas de Hedy S. R. de Vasconcelos.

Saúde, meio ambiente e questões indígenas: traz enfoques teóricos sobre medicina tradicional e programas de saúde; medicinas tradicionais e medicina ocidental; sistemas oficiais de saúde; epidemiologia e saúde dos povos indígenas. Os espaços acadêmicos que apareceram como referências foram:

- O Museu Emilio Goeldi, de Belém, com a abordagem antropológica e a referência aos povos indígenas da Amazônia.

- A Fundação Osvaldo Cruz, com a abordagem epidemiológica.

2 - No período bibliográfico de 2003, a temática indígena aparece em outro recorte, que se refere a sua articulação com o eixo ambiental no currículo escolar, sendo construída teoricamente a partir da abordagem antropológica e trazendo referências clássicas, como Darcy Ribeiro, Roberto Cardoso de Oliveira, Roberto da Matta, Roque de Barros Laraia, e, na geração atual, João Pacheco de Oliveira e Eduardo Viveiros de Castro.

3 - Ensino de ciências - Emergente nos períodos bibliográficos de 2004, 2005 e 2007, esse campo teórico articula questões ambientais e questões epistemológicas e pedagógicas sobre o método científico e a 
formação em ciências. Três principais tendências apareceram, sendo que, nas duas últimas, D. Delizoicov destaca-se como principal referência. São elas:

- Referências em que a ênfase teórica é na produtividade econômica como diretriz da formação científica, a partir do campo mais amplo da reflexão sobre o ensino das ciências, no qual é dominante a tendência a considerar apenas a articulação das ciências chamadas exatas ou naturais (Física, Química, Biologia e, às vezes, Matemática) com a tecnológica capitalista. As principais referências são artigos da década de 1980 da revista Daedalus, da Academia Americana de Artes e Ciências de Cambridge.

- Ênfase na articulação entre questões teóricas da interdisciplinaridade e da complexidade, por um lado, e política e cidadania, por outro, ao tratar das questões ambientais na formação do professor de ciências. Nessa perspectiva, destacaram-se A. Chassot e D. Delizoicov, sendo que este último articula a reflexão teórica sobre o ensino de ciências com o campo das ciências humanas aplicadas.

- Uma terceira tendência teórica aborda as questões da formação no campo científico a partir da relação ciência-sociedade, e do caráter coletivo da produção científica. Destacaram-se três direções importantes:

- Articulando questões ambientais com a educação médica, a referência à epistemologia de L. Fleck fundamenta uma série de trabalhos tratando da sociogênese da teoria da ciência e a epistemologia da medicina e das ciências biomédicas. Destacaram-se M. A. Da Ros e D. Delizoicov.

- Questões teóricas sobre a produção coletiva do conhecimento científico, colocadas por um grupo de pesquisadores da Universidade Federal de Santa Catarina, com formação na área médica e na área da educação, apareceram como referência para o ensino de ciências nas áreas de genética, medicina homeopática e história da biologia.

- Por fim, apareceram referências a trabalhos que analisam o campo do ensino de ciências a partir de mapeamentos da produção acadêmica sobre a temática ambiental, destacando-se D. Delizoicov.

4 - O campo teórico das representações sociais emergiu como importante referência conceitual para a EA nos períodos bibliográficos de 2004, 2005 e 2006, destacando-se as abordagens da psicologia social, com S. Moscovici e D. Jodelet, as pesquisas sobre opinião pública e visão de especialistas a respeito da questão ambiental, com os trabalhos de A. Trigueiro e S. Crespo, e o trabalho de M. Reigota sobre representação social e meio ambiente. 
5 - Sustentabilidade, regionalização e políticas ambientais - nesse campo teórico emergente a EA é pensada a partir de dois recortes epistemológicos:

- A articulação entre os conceitos de desenvolvimento, sustentabilidade e educação (2003), tendo como principais referências Marcel Bursztyn, Eduardo Viola e Hector Leis.

- A reflexão sobre educação e desenvolvimento regional, com ênfase na Amazônia (2005 e 2006), tendo como principais referências Michele Sato, Berta Becker, Milton Santos, Carlos Walter PortoGonçalves, R. Pasquis e L. Emperaire.

6 - Filosofia e natureza foi um campo teórico emergente nos períodos de 2003, 2005 e 2006, que aborda a articulação da EA com a ética, a estética, o feminismo, a relação entre tradição e iluminismo, tendo forte vinculação (embora não apenas) com os três trabalhos apresentados por Mauro Grün ao GT22 nesses períodos, sendo ele próprio também referenciado em outros artigos nesse campo. As principais referências foram a hermenêutica filosófica de H. G. Gadamer, a filosofia da linguagem de M. Bakhtin, a filosofia do romantismo, a partir de Gerd Bornheim, e a literatura feminista das décadas de 1980-90 sobre a relação entre gênero, ecologia e ciência. Michel Serres, Adorno e Horkheimer complementam os fundamentos filosóficos desse campo.

7 - No período bibliográfico de 2004, um campo teórico emergente se destacou a partir de fundamentos de dinâmicas de grupo, trazendo referências da psicologia social, com base principalmente em Kurt Lewin (teoria de campo em ciência social) e J. L. Moreno (sociometria e psicodrama).

8 - Nos anos de 2005 e 2006, o subcampo teórico da relação entre EA e literatura brasileira, destacaram-se os conceitos de história cultural e identidade nacional, tendo como referência principal a obra de Antônio Cândido.

9 - No período bibliográfico de 2006, destacaram-se também dois outros campos teóricos emergentes:

- A partir da relação entre educação e novas tecnologias, com base principalmente em Pierre Lévy e Umberto Eco, colocam-se os conceitos de rede virtual de aprendizagem, ecologia digital, cibercultura e práticas de recepção a produtos midiáticos.

- A interface entre EA e as questões urbanas é tratada a partir da 
ecologia e da geografia, com base principalmente em Milton Santos e Henri Acselrad, articulando questões sobre cidadania, meio ambiente urbano, territorialidade e globalização.

A seguir, serão apresentadas as tendências metodológicas identificadas no mapeamento da produção acadêmica analisada.

\section{Eixo 3 - Tendências metodológicas}

A análise das tendências metodológicas seguiu procedimentos semelhantes aos dos eixos anteriores, já descritos. A partir dos resumos descritivos, elaborou-se um quadro-síntese com as metodologias correspondentes aos trabalhos analisados no período de 2003 a 2007.

Os aspectos metodológicos foram analisados num recorte temporal e utilizando duas categorias de análise: as abordagens metodológicas e as técnicas e os procedimentos utilizados e relatados nos trabalhos.

A análise dos aspectos metodológicos identificou a predominância de duas vertentes de estudos: uma caracterizada pela abordagem qualitativa, com ênfase na pesquisa-ação e nas pesquisas participantes, já mencionada nas tendências temáticas que configuraram o primeiro eixo de mapeamento; e outra caracterizada pelo ensaio teórico e pelos estudos bibliográficos. A pesquisa-ação tem em René Barbier sua principal referência, enquanto que os estudos de análises de conteúdo apóiam-se em Laurence Bardin.

$\mathrm{Na}$ perspectiva temporal, observa-se que inicialmente houve predomínio da abordagem qualitativa e que a pesquisa-ação surge com um trabalho em 2003 e vai ganhando espaço ao longo dos anos. A partir de 2004, há um equilíbrio entre essa abordagem e as pesquisas bibliográficas e os ensaios teóricos, embora, como apresentado nos eixos temáticos e teóricos, a abordagem seja qualitativa. Apenas três trabalhos durante todo o período analisado relataram uso de abordagem quantitativa.

Entre as estratégias metodológicas utilizadas, observa-se ao longo dos anos a predominância da entrevista semiestruturada e da observação participante, seguida pela história de vida. Alguns casos relataram o uso de diário de campo e de questionário, sem, no entanto, explicitar as características desse instrumento, se utilizava questões abertas ou fechadas e o tipo de escala de medida, quando fosse o caso. 
Apesar das características qualitativas destacadas, observa-se, no geral, que a parte metodológica dos trabalhos analisados muitas vezes é imprecisa, vaga e até mesmo inexistente, dificultando a compreensão dos estudos relatados por parte dos leitores, além de impedir a replicação dos mesmos ou a comparação de resultados em estudos semelhantes.

\section{Conclusões}

A partir deste estudo, podem-se tecer algumas conclusões, que certamente não esgotam as possibilidades de leitura do mapeamento das tendências da produção acadêmica em EA do GT22 da Anped.

Em termos da regionalização da produção acadêmica no país, os trabalhos apresentados no período analisado representam particularmente o eixo sul-sudeste do Brasil. Isso pode indicar tanto a hegemonia dessas regiões quanto a necessidade de incentivar a participação das demais regiões brasileiras nesse espaço de divulgação e discussão acadêmica. Essa predominância do eixo sul-sudeste pode refletir a consolidação de programas de pós-graduação, mas também a dificuldade de acesso de pesquisadores de regiões mais distantes da sede desse evento, além de custo elevado para submeter trabalhos e participar dele.

Entretanto, o presente trabalho analisou apenas a produção apresentada nas reuniões nacionais da Anped. Seria, portanto, interessante, realizar estudos adicionais que permitissem comparar esse quadro com outros espaços que também acolhem a produção sobre EA, como, por exemplo, as redes regionais de EA, que surgiram praticamente no mesmo momento histórico de emergência do GE em EA da Anped (por volta de 2002-2003), os fóruns nacionais e regionais de EA, e o GT de Meio Ambiente, Sociedade e Educação, da Associação Nacional de Pós-Graduação e Pesquisa em Ambiente e Sociedade - Anppas, a fim de identificar se a predominância das produções oriundas do eixo sul-sudeste brasileiro se confirma nesses outros eventos. Vale ressaltar que nas reuniões regionais da Anped ocorridas no ano de 2008 também foram apresentados e debatidos trabalhos na área de EA.

Tomando-se como referência o recorte temporal, percebe-se que ao longo dos anos vai havendo o distanciamento da visão conservacionista e o surgimento da visão crítica da EA, que passa a predominar 
nos últimos dois anos. A abordagem socioambiental, que reconhece aspectos políticos e culturais como constitutivos de uma nova postura epistemológica, crítica e implicada, é notável no conjunto dos trabalhos analisados.

A Educação Ambiental nas instituições de educação formal e a formação de professores no sentido estrito constituem a temática predominante em todos os anos pesquisados. A presença dos temas pedagógicos e o reconhecimento da EA como espaço de mediação entre a escola e os problemas ambientais contemporâneos é visivelmente marcante. É possível que o foco nesse lócus de pesquisa favoreça a emergência e o crescente interesse pelos temas pedagógicos nos trabalhos apresentados.

A pluralidade temática e teórica, característica constitutiva do campo ecológico-ambiental, confirma-se nas pesquisas estudadas, que articulam o campo ambiental e a educação. A diversidade de temas e de campos teóricos emergentes demonstra essa pluralidade de saberes complementares e inclusivos.

No que se refere aos fundamentos teóricos, destaca-se a ênfase dada à discussão sobre a própria identidade da EA, a diversidade de linhas teóricas e de concepções, e o uso da concepção de práxis educacional sustentada na visão de Paulo Freire.

Outros fundamentos que se destacam na construção epistemológica da EA referem-se ao campo teórico da complexidade e da construção transdisciplinar do conhecimento, além de uma esfera de articulação entre os campos teóricos da ecologia, da cultura, da ética, da política e da formação da cidadania.

É possível, também, identificar algumas linhas teóricas transversais que integram a pluralidade temática das abordagens, como representações sociais, subjetividade, sustentabilidade, fenomenologia e hermenêutica, sendo estas utilizadas como fundamento para problematizar a conceituação da relação entre cultura e natureza.

Com relação às tendências metodológicas, pode-se constatar que, no geral, nos trabalhos analisados, a parte referente ao método quase sempre é negligenciada. A maioria dos autores dedica pouca atenção à explicitação da matriz teórico-metodológica utilizada em seus estudos, especialmente no que diz respeito à descrição do método, deixando a cargo do leitor as devidas inferências. Considera-se que essa omissão 
fragiliza a produção acadêmica na área, o que deve merecer atenção dos autores, bem como daqueles que analisam e julgam a submissão de trabalhos a serem apresentados, tanto nesse como em outros eventos que tratem dessa temática.

Apesar da fragilidade metodológica observada nos trabalhos analisados, percebe-se forte predominância da abordagem qualitativa, com ênfase na pesquisa-ação e nas pesquisas participantes. É possível que o momento de transição paradigmática, a crise de valores e os conflitos socioambientais da atualidade, aliados à reflexão do campo da educação e da Educação Ambiental, com seus referenciais na complexidade sistêmica da vida, em suas relações e inter-relações, contribuam para a ênfase de estudos qualitativos, que buscam aprofundamento da compreensão da realidade investigada.

Percebe-se, também, que esses estudos participativos enfatizam a intervenção na realidade, de forma a modificar a relação que os sujeitos têm consigo mesmos e com seu entorno. Isso pode sinalizar a vocação das pesquisas em Educação Ambiental para a transformação da realidade, em direção a relações mais sustentáveis para a pessoa, os grupos, a sociedade e o planeta, num processo de ação-reflexão-ação permanente.

Apesar do recorte de cinco anos em um evento nacional específico, o presente trabalho permite identificar o cenário e as características da produção acadêmica na área de Educação Ambiental, considerando sua dinâmica e apontando a emergência de aspectos temáticos e teóricos no âmbito desse contexto, além de evidenciar as omissões e os temas e referenciais silenciados pelos pesquisadores da área, que podem sugerir interesses futuros de investigação.

Espera-se, com isso, suscitar a reflexão da área de Educação Ambiental e a identificação de sua realidade, especialmente do GT22 da Anped, contribuindo para o debate acerca da produção acadêmica específica e geral no que diz respeito a essa temática, além de favorecer a consolidação desse espaço na estrutura da Anped. 


\section{Referências}

BARBIER, R. A pesquisa-ação. Brasília: Líber Livro, 2004. Série Pesquisa em Educação. v. 3. BARDIN, L. Análise de Conteúdo. Lisboa: Edições 70, 1997.

CARVALHO, I.C. Invenção e auto-invenção na construção psicossocial da identidade: a experiência constitutiva do educador ambiental. In: GUIMARÃES, M. (Org.). Caminhos da Educação Ambiental. Campinas, SP: Papirus, 2006.

SATO, Michèle; Santos, José Eduardo. Tendências nas pesquisas em Educação Ambiental. In: NOAL, F.; BARCELOS V. (Orgs.). Educação Ambiental e Cidadania: cenários brasileiros. Santa Cruz do Sul: Edunisc, 2003.

\section{Notas}

${ }^{1}$ Agradecimentos a Aurelice da Silva Vasconcelos, Daniella Ungarelli, Isabel Figueiredo, Magda Pinto, Maristela Nascimento Sousa, Pejman Samoori e Rosana Gonçalves da Silva, estudantes do Mestrado e do Doutorado em Educação e Ecologia Humana do Programa de Pós-Graduação em Educação da Universidade de Brasília, que realizaram análises preliminares da produção acadêmica objeto do presente trabalho.

${ }^{2}$ Trabalho apresentado na $31^{a}$ Reunião Anual da Associação Nacional de Pós-Graduação e Pesquisa em Educação - ANPED, sob encomenda do Grupo de Trabalho de Educação Ambiental (GT22).

Recebido: 15/09/09

Aprovado: 22/09/09

Contato:

Universidade de Brasília Faculdade de Educação Departamento de Teoria e Fundamentos Campus Universitário Darcy Ribeiro Asa Norte Brasília - DF CEP 70910-900 